\title{
Variaciones sobre un episodio de Facundo. Autores en proceso: Domingo F. Sarmiento, José M. Paz y Eduarda Mansilla
}

Fecha de aprobación: 13 de mayo de 2019

Fecha de recepción: 17 de septiembre de 2019

\section{Resumen}

El siguiente escrito parte de la lectura de una anécdota protagonizada por Facundo Quiroga y contada por Sarmiento en el capítulo "La ciudadela" de su libro Facundo. El anecdotario de las guerras civiles de mediados del siglo diecinueve acumula más de una versión acerca de episodios que reúnen similares características, entramado que nos permitió abordar la secuencia como un corpus de estudio. José María Paz en sus Memorias y Eduarda Mansilla en Pablo o la vida en las pampas retoman la anécdota de Sarmiento, pero alternan los personajes que la interpretan a la vez que habilitan lecturas contrapuestas. Por otra parte, realizaremos además un relevamiento de la condición autoral, principalmente cuando abordemos las fuentes textuales y pictóricas de la escritura sarmientina.

Palabras claves: autoría; Facundo; Domingo F; Sarmiento; Eduarda Mansilla; José M. Paz.

Citar: Dellarciprete, R. (abril-junio de 2020). Variaciones sobre un episodio de Facundo. Autores en proceso: Domingo F. Sarmiento, José M. Paz y Eduarda Mansilla. La Palabra, (37), 87-98. doi https://doi.org/ 10.19053/01218530.n37.2020.9440

\section{Rubén Dellarciprete}

Doctor en Letras de la Universidad Nacional de La Plata. Realizó estudios de posgrado - especialización en Literatura Comparada y especialización en Literatura Digital- en la Universidad de Barcelona. Jefe de Trabajos Prácticos en Literatura Argentina I, Facultad de Humanidades y Ciencias de la Educación de la Universidad Nacional de La Plata. Investigador del Centro de Literatura y Literaturas Comparadas (IDIHCS-UNLP). Correo electrónico: dellarcipreteruben@gmail.com.

* Artículo de reflexión enmarcado en el proyecto de investigación titulado: De la memoria a la Historia. Aportes, debates y desafíos para un campo en consolidación. Secretaría de Ciencia y Técnica, Universidad Nacional de La Plata. Universidad Nacional de La Plata

Dhttps://orcid.org/0000-00025785-1143 


\title{
Variations on An Episode of Facundo. Authors in Process: Domingo F. Sarmiento, José M. Paz and Eduarda Mansilla
}

\begin{abstract}
The following writing starts off with the reading of an anecdote starring Facundo Quiroga and told by Sarmiento in the chapter "The Citadel" of his book Facundo. The anecdote of the civil wars of the mid-nineteenth century accumulates more than one version about episodes that have similar characteristics, a framework that allowed us to approach the sequence as a corpus of study. José María Paz in his Memoirs and Eduarda Mansilla in Pablo or life in the pampas, take up the anecdote of Sarmiento but alternate the characters that interpret it while enabling conflicting readings. On the other hand, we will also carry out a survey of the author's condition, mainly when we approach the textual and pictorial sources of the Sarmientina script.
\end{abstract}

Keywords: Autorship; Facundo; Domingo F; Sarmiento; Eduarda Mansilla; José M; Paz. 


\section{La Ciudadela: mediaciones visuales y textuales}

El siguiente artículo parte de la lectura de una anécdota protagonizada por Facundo Quiroga y contada por Domingo F. Sarmiento en su libro Facundo. La misma habría tenido lugar en el entorno de la ciudad de Tucumán durante el año 1831. El anecdotario de las guerras civiles de mediados del siglo diecinueve acumula más de una versión acerca de episodios que reúnen similares características, entramado que me permitió abordar la secuencia como un corpus de estudio. Al texto de Sarmiento, sumo los hechos contados por el general José María Paz en sus Memorias, así también un pasaje del último capítulo de Pablo o la vida en las pampas de Eduarda Mansilla, quien, en su interés por dialogar acerca de los valores fundacionales de la modernidad nacional argentina, retoma la anécdota sarmientina para proponer una lectura alternativa al modelo binario elaborado por el sanjuanino.

Desde su mismo inicio, el capítulo 12 de Facundo presenta una metodología compositiva compleja. El capítulo "Ciudadela" está encabezado por un epígrafe del geógrafo Conrad Malte-Brun. El breve texto asocia la costumbre de los habitantes de la ciudad de Tucumán, quienes se reúnen a cantar rodeados de una naturaleza pródiga, con situaciones míticas descriptas por Virgilio y Teócrito. La comparación que introduce dos autoridades literarias coloca la descripción geográfica de Brun en continuidad con la práctica discursiva que proponía por aquel entonces Alex Von Humboldt. No tan solo "revestir la ciencia con una forma literaria" sino también darle relieve cultural (1999, p. 30).

El procedimiento de vincular los fenómenos naturales con la tradición literaria canonizada es un recurso constante en los escritos de Von Humboldt. En Cosmos, por ejemplo, entre múltiples referencias a la literatura contemporánea o clásica, reflexiona sobre las características y el comportamiento del mar en relación con las personificaciones de la Teogonía de Hesíodo o con la escuela de los aedas de Beocia (Von Humboldt, 1875, p. 124). De este modo, en línea con Malte-Brun y Von
Humboldt, Sarmiento se incluye dentro del circuito discursivo de su tiempo, a la vez, que oficia de traductor cultural de las prácticas escriturarias civilizantes.

Como señalamos, cuando el narrador emprende la descripción geográfica de la región en que se desarrollan los hechos, se vale del manual de Malte-Brun, pero también del relato de viajero de Joseph Andrews, Journey from Buenos Aires. Interesado y preocupado por representar y reflexionar sobre el territorio nacional, tema alrededor del cual se deberá organizar la geopolítica y el sistema económico del país, Sarmiento nos muestra una realidad extraída de los textos.

En algunas oportunidades cita de manera literal, como el caso del epígrafe de Malte-Brun, en otras elabora una paráfrasis literaria, por ejemplo, con la información que extrae directamente de Journey from Buenos Aires y, según Noel Salomón, de Memoria descriptiva sobre Tucumán de Juan Bautista Alberdi'. Por medio de una técnica pintoresquista o paisajista, si se quiere, Sarmiento registra la belleza de

\footnotetext{
Noel Salomón en su libro Realidad, ideología y literatura en el Facundo de D. F. Sarmiento (1984), capítulo: "La descripción de Tucumán en el Facundo", realiza un detallado seguimiento comparativo entre las lecturas explícitas y las lecturas implícitas que proveen material de escritura a Sarmiento al momento de describir la naturaleza tucumana (pp. 75-90). Estructura el estudio en cinco procedimientos y va estableciendo las relaciones entre las fuentes y la reescritura sarrmientina. El punto de partida es Memoria descriptiva sobre Tucumán de Juan Bautista Alberdi, los textos ya citados de Malte-Brun y Andrews, e incluye, posibles remanencias de Paul et Virginie de Bernardin de Saint Pierre y Atala de Chautebriand como así también la inflexión ilustrada o pre-romántica de Rousseau a través de Memoria de Alberdi. Adolfo Prieto en el capítulo "Domingo F. Sarmiento" de su libro Los viajeros ingleses (2003) cita a Salomón dándole continuidad a su línea argumentativa (pp.198201).
} 
los alrededores de la ciudad a la par que recrea también la cultura del ocio que practican sus pobladores ${ }^{2}$ :

[...] apártanse las naranjas que embarazan el paso, si es el otoño, o bien sobre la gruesa alfombra de azahares que tapiza el suelo, se balancean las parejas de baile, y con el perfume de sus flores, se dilatan, debilitándose a lo lejos, los sonidos melodiosos de los tristes cantares que acompaña la guitarra. ¿Creéis por ventura, que esta descripción es plajiada de las Mil $i$ una noches, u otros cuentos de Hadas a la oriental? (Sarmiento, 1938, p. 217)

Como se puede apreciar en la cita, el autor describe la geografía tucumana y las costumbres de sus habitantes por medio de una elaboración retórico-literaria que podemos relacionar con el tono melodramático propio de la estética romántica de la época. Todo -retórica y tonocrea un ambiente que responde a un interés político definido: romantizar el contexto donde va a introducir por contraste a la fiera, no menos literaria que su entorno. Sarmiento pone de manifiesto su oficio: lee, copia-reproduce-reescribe, mientras su protagonista descansa envuelto en un paisaje arcádico.

Por otra parte, Sarmiento no tan solo dialoga o comparte recursos con escritores europeos, sino también, reelabora episodios que, como señalamos con anterioridad, forman parte del anecdotario de las guerras civiles.

Una vez consumado el triunfo de sus tropas, Quiroga toma posesión de una enramada sombría. Mientras descansa, atiende los protocolares pedidos de clemencia de los vencidos:

Una diputación de niñas, rebosando juventud, candor i beldad, se dirije hácia el lugar donde Facundo yace reclinado sobre su poncho. La mas resuelta o entusiasta camina adelante; vacila, se detiene, empújanla las que le siguen: páranse todas, sobrecojidas de miedo, vuelven las púdicas caras, se alientan unas a otras, i deteniéndose, avanzando tímidamente i empujándose entre sí llegan al fin, a su presencia. Facundo las recibe con bondad; las hace sentar en torno suyo, las deja recobrarse, e inquiere al fin el objeto de aquella agradable visita. Vienen a implorar por la vida de los oficiales del ejército que van a ser fusilados. Los sollozos se escapan de entre la escojida i tímida comitiva [...] Facundo está vivamente interesado, i por entre la espesura de su barba negra alcanza a discernirse en las facciones la complacencia y el contento. Pero necesita interrogarlas una a una, conocer sus familias, la casa dónde viven, mil pormenores que parecen entretenerlo i agradarle, y que ocupa una hora de tiempo, mantiene la expectación i la esperanza. $\mathrm{Al}$ fin, les dice con la mayor bondad: ¿No oyen ustedes

Sobre el arte pintoresco o el aprendizaje de la cultura estética frente a la naturaleza ver Williams Gilpin, "Essay I-II-III on picturesque beauty", que pertenece a Three essays: on picturesque beauty: on picturesque travel; and on sketching landscape: to which is added a poem, on landscape painting (4-88). Ver también Larry Shiner, La invención del arte (191-192 y 425). 
esas descargas? (Sarmiento, 1938, pp. 217-218)

\section{Le 9 Thermidor de Monvoisin, pintura a la que Sarmiento rin- de homenaje en su artículo pu- blicado en el Progreso, el 8 de marzo de 1843, representa un momento clave de la Revolu- ción francesa, la caída de Ro- bespierre (Sarmiento, 1948, pp.}

124-129). Su particular técnica reside en que la tensión dramática se sustenta en la progresión envolvente que sugiere el efecto de movimiento. La dramatización de la caída de Robespierre se resuelve sobre una imagen que gira teatralmente sobre un foco de atención, que es el político en debacle. La historia, tensión entre fuerzas contra- puestas, se ha focalizado sobre Robespierre, coptado por un poder que lo arrebata, lo arranca del lugar que ocupa en la Francia moderna.

La figura de Facundo en la
enramada es diametralmente
opuesta. Él se erige en el cen-
tro a partir del cual se produce
el movimiento coreográfico de

Con relación a esta cita me propongo un breve excursus reflexivo sobre el problema que significa editar la obra de Sarmiento y las posibles consecuencias o condicionamientos sobre su lectura. He constatado que en algunas publicaciones contemporáneas de Facundo (Cátedra 2005, Losada 2008 Colihue 2010, EUDEBA 2011) la puntuación varía de manera notable. Las modificaciones gramaticales para adaptar el texto al uso actual de la lengua resultan comprensibles, pero las variables de ritmo y entonación que implican los cambios de la puntuación atentan contra la resolución formal que pudo haber imprimido Sarmiento. Podría sugerirse como ejemplo la publicación de la Biblioteca Ayacucho en 1977. Las editoras, Nora Dottori y Susana Zanetti, declaran que utilizaron a su vez la edición de Alberto Palcos de 1938, a modo de fuente, aunque "con la salvedad de que hemos modernizado la grafía -muy personal en Sarmiento- y la puntuación" (Sarmiento, 1977, p. LIV). Modificar la grafía resulta justificable, ahora, intervenir la puntuación puede conducir a un autor distinto. La cita que sigue tomada de la edición Ayacucho, podría demostrar lo que queremos significar: "La más resuelta o entusiasta camina adelante; vacila, se detiene, empújanla las que le siguen, páranse todas, sobrecogidas de miedo, vuelven las púdicas caras, se alientan unas a otras, y, deteniéndose, avanzando tímidamente y empujándose entre sí, llegan, al fin, a su presencia” (Sarmiento, 1977 p. 176). El intercambio de los dos puntos por la coma después de "le siguen" es aceptable, pero la continuidad que las editoras dan al uso de las comas en las frases siguientes, en busca de pausas - por otra parte, gramaticalmente correctas- lo que logra es ralentizar el ritmo y la dinámica melodramática del pasaje. Convierte la narración en una descripción que intenta explicar. Es decir: convierte en académica una escritura que en principio responde a intereses diferentes. Dadas las circunstancias ¿̇resulta aceptable el intento de emprolijar la escritura de Sarmiento? Una edición escolar podría explicar semejante decisión, aunque no sería el caso de la Biblioteca Ayacucho. La determinación de modificar una obra original no es una práctica aceptada en las otras artes, fuera de la literatura. Los restauradores de cuadros, frescos o murales no se atreverían a intervenir la paleta o la línea del dibujo, bajo ninguna circunstancia. Cuando les toca levantar un trabajo tapado por otro posterior o por la inclemencia del desconocimiento, la consigna principal del restaurador es encontrar el original, reproducir el original del modo más fiel posible. Las variaciones pueden ser producto de la impericia del ejecutante ocasional o de la barrera que presenta la obra debido a su grado de deterioro. Nunca sería consecuencia de la decisión del restaurador. En el caso de la música, la relación entre original y reproducción es completamente diferente. La reproducción de la escritura musical siempre se convierte en una zona fronteriza porque la música no tiene otra manera de corporizarse sino mediante la interpretación. "La música es sonido y existe en el momento en que se toca" (Barrico, 2008, p. 32). Si bien pueden encontrarse ejecuciones filológicas o dactilográficas, dependen en menor o mayor grado de la interpretación que realice el músico o arreglador de turno, interpretación válida, incluso cuando llevada al extremo, el ejecutante dispone de lecturas sumamente personales. Por lo tanto, en el caso de una obra literaria se convalida la hermeneusis que implica una lectura crítica, pero se torna cuestionable la reescritura del original por parte de los editores, intervención, por otra parte, aceptable cuando se trata de una performer artística. Si el editor reescribe el texto nos encontramos frente a una recreación que se puede aceptar cuando se dirige a un receptor en particular, no a lectores en general y mucho menos cuando se dispone para su estudio crítico filológico. En este caso, preferí trabajar sobre la edición Palcos (Sarmiento, 1938), con el fin de liberar la interpretación a nuestro propio criterio de mediación. Como se podrá observar, la breve narración de los hechos enmarcados en la cita supra, es una escena compuesta de manera visual y dinámica, casi la descripción de una representación teatral o dramatización. Los personajes femeninos se mueven en relación con el centro de atención del espectador, Facundo. La representación tampoco se encuentra distante de las pinturas románticas, que tienen como motivo o tema un acontecimiento político histórico. Sarmiento tenía un singular interés por las pinturas de corte escénico. En la carta "Roma" de su libro Viajes, dirigida al obispo de Cuyo, enumera monumentos, detalles arquitectónicos, esculturas y destaca su inclinación por los murales o cuadros que desarrollan una secuencia bíblica, histórica o familiar (Sarmiento, 1996, pp. 217-222). Surgen los nombres de Rafael y Miguel Ángel, cuando cita maestros del pasado y los nombres de Coghetti, Chatelain, Podesti, entre los contemporáneos. Todos con una marcada inclinación por las pinturas escénicas. Lo mismo ocurre cuando compara el arte romano del presente con el español. Si bien su referencia al vacío cultural de la España moderna se lleva el peso de la reflexión, cuando cita los modelos, aparecen Velázquez y Murillo, dos referentes del espacio pictórico y la perspectiva. Sus pinturas de personas individuales o grupos que remiten a una situación histórico-religiosa determinada o a situaciones socioculturales, formulan, por medio del contraste de luces y el escalamiento espacial, una escenificación de la imagen. La preferencia de Sarmiento por obras en las que predomine lo escénico, probablemente tenga relación directa con la posibilidad de buscar y encontrar tramas, tejidos, en definitiva, huellas de legibilidad histórica por sobre la gráfica gramatical del dibujo puro, desprovisto de composición. 
"las niñas", pero al revés de Robespierre, inmovilizado por las tensiones, Facundo controla la dinámica de la historia. Quiroga, a quien una y otra vez a lo largo de su biografía lo encontramos encarnando actitudes violentas, desbordado por conductas compulsivas, en el cuadro de la Ciudadela, por el contrario, se muestra dueño de un temperamento mesurado, especulativo, como si se tratara de la figura liminar de Rosas. El arte de narrar esta secuencia reside en no desestabilizar el ritmo y controlar el tono en un registro medio, procedimiento opuesto al que Sarmiento por lo general es afecto y por el cual resultó enjuiciado por sus contemporáneos (Alsina, Echeverría, Alberdi).

En la misma escena, el énfasis, que con frecuencia distingue a su protagonista, se desplaza hacia el sector de sus oponentes. El tono medio sube una octava cuando Sarmiento compone el carácter y el comportamiento de las niñas que se dirigen a solicitar clemencia para sus novios, maridos o padres. Un lector de hoy día, difícilmente se sienta cómodo con la sensiblera introducción de la diputación. El relieve puesto en la timidez, el candor, la beldad e inocencia de las jóvenes toca un extremo sentimental que sobre evidencia su interés de conducir al receptor a tomar partido.

Con oficio, Sarmiento conduce la narración entre orillas opuestas. Por otra parte, en pocas líneas realiza un despliegue consumado del campo visual, trabaja con el paisajismo o pintoresquismo del entorno, crea una escenificación pictóhistórica, si pensamos en Le 9 Thermidor o una dramatización si recordamos la coreografía que despliegan las mujeres. La artesanía del montaje lecto visual en ningún momento extravía las intenciones políticas que, por lo común, se entiende como interés que precede al texto, aunque nada nos impide pensar la emergencia de lo político en términos de producción artística a medida que el proceso de escritura avanza y no necesariamente en términos de ficción, como lo sugirió Ricardo Piglia (1999, p. 20).

Entre líneas, versiones de José María Paz y Eduarda Mansilla

Sarmiento escribe sin ver, aunque hace uso de una palabra visual. Escribe sin conocer de manera directa la realidad que aborda; utiliza la red de textos como apoyatura y reproduce la sensibilidad artística de la época. Media entre autores, obras y lectores. La utilización de Con- rad Malte-Brun, Alexander Von Humboldt, Joseph Andrews, Raymond Monvoisin parece confirmar la teoría post estructuralista respecto del nombre autoral. El escritor resulta un moderador $\mathrm{u}$ operador de los textos que circulan en la red literaria. Regular, administrar, controlar, reformular por medio de la escritura ${ }^{4}$.

Se pueden poner en consideración también, los préstamos de la oralidad que Sarmiento administra y Alberdi enjuicia como si se tratara de un disvalor literario. "No es nada" -dice Alberdi- "que el Facundo llénase a su autor, en cierto modo nominal, del crédito que en rigor pertenecía a los contribuyentes de las ideas y noticias de que se compone el libro". (Alberdi, 1962, p. 285).

Si bien la cita debe entenderse como un acierto descriptivo de Alberdi, al modo textualista de mediados del siglo $\mathrm{xx}$, se trata, sin embargo, de un desacierto crítico. El mérito no reside en proveer el material discursivo sino en la capacidad de administrarlo literariamente, operación que destaca la labor de Sarmiento como escritor. "De ahí viene que el Facundo es un museo de estilos, de opiniones y de doctrinas políticas [...]" (Alberdi, 1962, p. 285). Referencia crítica de Alberdi que

En esta línea de pensamiento seguimos a Roland Barthes en “La muerte del autor” (2013) y a Michael Foucault en “¿Qué es un autor?” (1999). 
no podemos menos que avalar y subrayar, pero no se debería desconocer que el valor agregado del museo de estilos y del ensamble de opiniones y doctrinas adquiere formalidad $\mathrm{y}$, en consecuencia, sentido, gracias al talento y oficio de Sarmiento, inferencia que reubicaría al sanjuanino en su lugar de pertenencia: el movimiento romántico y su concepción del genio creador. Por lo menos, en el siglo xIx, la incidencia del sujeto y su talento se pueden constatar en Facundo, a diferencia de lo enunciado por los estudios sobre la condición de autor un siglo después ${ }^{5}$.

Por otro lado, si Sarmiento pretende darle inteligibilidad a la barbarie nacional, la anécdota narrada -que no tiene una sola lectura-, en lugar de concentrar el problema en el campo federal, lo traslada también al campo civilizado o al menos a las prácticas de algunos de sus más encumbrados representantes. Sería el caso del general José María Paz, militar de laboratorio, a la europea, según el escritor de Facundo, quien narra en sus Memorias póstumas (2000) la misma situación, pero con otros actores.
Cuando Paz se disponía a relatar la batalla de la Tablada se vio en la necesidad de responder a los reclamos que La Madrid había expuesto en sus memorias ${ }^{6}$. La polémica entre los dos generales se desató cuando Aráoz de La Madrid señaló que, en la Tablada, Paz intentó sacrificarlo. El reproche del tucumano se podría dividir en tres puntos:

1) Haberlo hecho descender por una zona escarpada que remata en corrales de los cuales resulta casi imposible realizar una maniobra de escape. Es decir, lo envío a una muerte casi segura.

2) Paz atestó su división de milicianos sin experiencia de combate y desoyó su pedido de que equilibrara las fuerzas repartiendo por igual a los milicianos inexpertos en cada una de las divisiones y batallones.

3) Ante la solicitud de La Madrid, Paz le negó la incorporación del teniente coronel Pringles, de manera que debilitó aún más sus cuadros, de por sí escasos de personal idóneo en materia de logística militar.
La réplica de José María Paz se despliega en una explicación que intenta poner al descubierto la psicología paranoica de los oficiales de jerarquías intermedias o medias superiores. Sospechan que sus jefes los utilizan de señuelos distractores y sacrificiales, o los desactivan en posiciones intrascendentes con el objetivo de confinarlos en el olvido y el ostracismo. La Madrid levantó otras dos acusaciones en conexión con el pasillo de la muerte que le dispuso el general cordobés. Una lo tilda de estratega conservador, falto de audacia, que condujo a más de un desastre bélico y, la otra, que nos interesa particularmente, lo define como un jefe vengativo (La Madrid, 2007, pp. 360-436).

En este contexto de apremio, caracterizado como alguien que suele tomar represalias extremas, Paz intenta defenderse de los fusilamientos que le atribuyen después de vencer en la Tablada. En principio, utiliza como maniobra distractoria la crueldad de Facundo, imagen que había elaborado con todo detalle Sarmiento. Según Paz, la derrota de la Tablada y la inmediata recuperación de la

El reconocimiento del sujeto como ejecutor o administrador de discursos también se puede entender -nosotros lo hacemos en relación con la imagen, con la escritura visual de Sarmiento- en función de la musicalidad de la escritura. Marcelo Cohen en "Música prosaica" rescata la condición de operador que configura a un traductor -no era otra cosa Sarmiento, en definitiva, un traductor cultural-inclusive a un autor hasta la posibilidad de concebirlo como performer, modo de la emisión que no desdice, al contrario, enfoca la actuación de Sarmiento y sus textos (Cohen, 2014, pp. 21-27). No resulta conveniente, por economía y encuadre de nuestro análisis, indagar sobre el potencial musical de la lengua sarmientina y la performance de su escritura, en el que el sujeto, la obra y la puesta en escena se engendran unos con otros para adquirir sentido.

$6 \quad$ Las memorias de La Madrid fueron publicadas después que las de Paz, pero escritas antes. En 1850, Paz tuvo la oportunidad de leer los manuscritos que le facilitó Andrés Lamas, quien se los había comprado al general tucumano. La Madrid las escribió en Montevideo en 1841, las amplió en 1850 y fueron publicadas por Adolfo Carranza tiempo después de su muerte, en 1895 (Páez de La Torre, 2007, p. 8). 
ciudad no le permitieron a Quiroga ajusticiar a los prisioneros tomados en la plaza. Al cordobés, le bastó levantar la imagen del tigre sanguinario de la literatura, a pesar de la ausencia de ejecuciones, para posicionarse, discursivamente, como alguien compasivo dentro de la lógica terrorista que las guerras civiles imponían.

El modo de implementar los fusilamientos de la Ciudadela, que narró Sarmiento, obtiene su réplica en la actuación del general cordobés después de la Tablada. Una vez finalizada la batalla, José María Paz retoma el contacto con sus jefes en los alrededores de la plaza, antes sitiada, y se apresta a ingresar a la ciudad. Según Paz, el jefe del estado mayor, Deheza, había dispuesto fusilar a dos oficiales de Quiroga (Paz, 2000, p. 422). Ante la inminencia, Paz convoca al teniente coronel Francisco Borja Moyano y le ordena que "vuele" a detener las ejecuciones. Mientras Borja se dirige a cumplir con el mandato, Paz se distrae, detiene su paso para conversar con el gobernador de Tucumán, López, que se encuentra entre sus fuerzas. El tiempo pasa. Paz habla todavía con López cuando oye algunos disparos. Borja regresa y le explica: los disparos se debían a que había llegado a destiempo y no pudo detener la ejecución. Paz conjetura que el ánimo generalizado a favor de los fusilamientos había influido sobre Moyano, por lo tanto, no se apresuró en cumplir la orden. Al modo de Facundo con las jóvenes tucumanas, Paz dilata la conversación con López; sacando partido de su demora, alguien conspira y los fusilamientos se ejecutan. La inocencia de las niñas, análoga a la inocencia pretextada por Paz, no les permite ver que, a sus espaldas, se llevan a cabo los ajusticiamientos. Combinación fatal de circunstancias que "[...] han abultado mis enemigos y que han querido echar a mi cuenta" (Paz, 2000, p. 422). Si el general en jefe se entretiene conversando mientras se juega la vida de oficiales prisioneros a su cargo; si él mismo sugiere que su subordinado Moyano desobedece el mandato, su descargo se debilita. El narrador consciente de su falencia argumentativa, a lo Sarmiento, adopta el recurso de la cuantificación para fortalecer su defensa. Enumera, a modo de descargo, los prisioneros a los que les perdonó la vida e inclusive liberó: el coronel Brizuela, Juan Pablo Bulnes, Bárcena Paredes, el coronel Navarro.

No fue el único caso de ejecuciones en que se vio envuelto. Cuando José María Paz ingresa al bastión recuperado "las calles estaban desiertas, todas las puertas cuidadosamente cerradas, reinaba un profundo silencio y la ciudad parecía un pueblo sin habitantes" (Paz, 2000, p. 425). Una vez frente al recinto amurallado de la plaza, la columna se encuentra con un foso "que era preciso terraplenar" para que pase el ejército. En la parte exterior del foso, cinco hombres se encuentran atados y tendidos en el suelo. José Arguello los señaló como los asesinos de Tejedor. Paz, ante la efervescencia de los suyos, ordena que no los toquen. Necesita indagarlos. Ve que se acerca la comitiva del Colegio de Loreto: "[...] piqué mi caballo y me fui a recibirlos, y mientras recibía sus felicitaciones, me avisaron varios tiros de fusil que aquellos miserables eran sacrificados [...]". (Paz, 2000, p. 426). Las tres anécdotas, la de Facundo y las dos de Paz, son estructuralmente iguales, solo cambia el punto de vista del narrador. El acontecimiento del capítulo 12 del libro de Sarmiento lo narra un enemigo declarado del protagonista. Los ocurridos en Córdoba los cuenta el propio protagonista. El paso del tiempo y la conversación distractiva a uno lo sentencian y a otro lo eximen.

En Pablo o la vida en las pampas, Eduarda Mansilla dialoga con el diagnóstico y el proyecto de país que Sarmiento presenta en Facundo. Cuando tiene que resolver la novela, narra una situación homóloga a la contada por Sarmiento en la Ciudadela. La madre de Pablo, el protagonista, atraviesa un desdichado derrotero, primero en busca de su hijo y después del salvoconducto que lo deje en libertad. Pablo fue incorporado al ejérci- 
to unitario por la fuerza, a pesar de estar exceptuado. Su padre y hermanos habían muerto en la guerra con Brasil y, por lo tanto, el Estado lo documentó para liberarlo de prestar servicio y así pudiera trabajar y cuidar de su madre. El joven desertó dos veces, dos veces fue detenido y finalmente retenido como prisionero. Moreira, el comandante de las fuerzas unitarias, interpelado por la madre de Pablo para que libere a su hijo, no sabe leer. El salvoconducto escrito, en manos de un representante de la civilización, se convierte en un signo muerto. Vidal, el segundo a cargo, intervine en el diálogo y argumenta defendiendo al prisionero y pide por su excarcelación. La actitud de Moreira lo alienta para que desarrolle su alegato. Vidal aprovecha la oportunidad y se extiende en su exposición; defiende también a los paisanos de la campaña en general, no tan solo a Pablo. Moreira no detiene el excursus del oficial. El tiempo transcurre con lentitud. Mientras hablan, se oye una descarga que corta en dos la conversación, invirtiendo la lógica binaria sarmientina. Aquí, los bárbaros que fusilan de manera injusta no son los representantes de la campaña. A espaldas de una conversación que protagoniza un jefe unitario iletrado, los gauchos son ejecutados. Eduarda Mansilla retoma la anécdota de Sarmiento y deli- beradamente revierte el sentido (Mansilla, 2007, pp. 287-297) ${ }^{7}$.

Acorde a la cronología de los relatos, la saga se cerraría con Pablo o la vida en las pampas, aunque si incursionamos en el tiempo literario las referencias pierden convicción. Además, el valor de verdad, si es que tiene algún grado de importancia en este tipo de textos, se relativiza. Que Paz mienta o intente mitigar su responsabilidad en los fusilamientos para que no lo hermanen con la figura de Facundo, nos resulta incomprobable, pero verosímil. Tampoco parece definitivo que Sarmiento potencie su inteligibilidad de la barbarie exclusivamente por medio de su competencia literaria, barbarie que cruza las fronteras y anida también en el campo unitario, según Mansilla. El cuestionable comportamiento del vencedor de la Tablada y la malicia del unitario Moreira habilitan lecturas liberadas de algunas concepciones críticas, aferradas a presupuestos totalizantes. Alberdi, ni siquiera habría considerado la anécdota en cuestión, tampoco sus diversas variantes, como un dilema identitario. Muy probablemente habría adjudicado el accionar de los jefes militares a los crímenes de la guerra. "La guerra es la pérdida temporal del juicio. Es la enajenación mental [...] De una y otra parte, todo cuan- to hacen los hombres para sostener su derecho [...] es torpe, cruel, salvaje" (Alberdi, 2006, pp. 47-48). Si alguien puede mediar en esta locura según el autor, sería un juez externo desinteresado, condición que no reunirían Sarmiento, ni Paz, ambos involucrados en una de las facciones. Quizás sí, debido a sus circunstancias personales, Eduarda Mansilla (Alberdi, 2006, pp. 56-57).

\section{Formalizar la Historia}

Según Sandra Contreras, Sarmiento, en su artículo "Cuadros de Monvoisin", sostiene que Monvoisin es un pintor histórico, no solo porque pinta momentos históricos sino porque capta la pasión de la historia con sus cuadros (Sarmiento, 1948). "Artista, dice, es el que logra captar y traducir esa agitación histórica, para lo cual, agrega (y esto es lo capital) hace falta nada menos que talento creador" (Contreras, 2013, p. 38). Por esta línea de análisis, la vinculación de Sarmiento con la creación artística y la reproducción de la historia no deja de posicionarnos dentro de la versión mimética del arte. Si bien existe una diferencia entre reproducir las formas externas de la historia y captar la pasión que la moviliza, permaneceríamos igual dentro del

Según Francine Masiello, Eduarda Mansilla condena las prácticas políticas tanto de los federales como de los unitarios y formula por medio de sus ficciones un programa alternativo para "la reforma y la modernización del estado" (Masiello, 1997, pp. 55-61). 
repertorio mimético como modalidad creativa.

Entender la relación arte-historia, por medio de un recorrido diametralmente opuesto, no implicaría perder por ello el vínculo entre uno y otra. Si seguimos el razonamiento de Contreras, la representación que elabora Sarmiento tendría como referente un orden subyacente de la realidad, no el visible e inmediato. Esta clase de representación, Elías Palti (2004), que se vale a su vez de la clasificación pensada por Tatarkiewicz (2001), la denomina mimesis physeos, a diferencia de la concepción primaria que remite a copiar la apariencia externa de la realidad. Según Palti (2004), Sarmiento, en Facundo, acude a la creación literaria porque de otro modo existen fenómenos de la realidad nacional que le resultan indecibles (p. 539). Artificio que podría ser adjudicable a su versión de la barbarie que no se encuentra dentro de la traducción de Historia que conoce y practica Sarmiento, porque justamente es su negación (p. 529). La siguiente cita de "Cuadros de Monvoisin" podría dirimir cualquier discusión al respecto:

"La pintura de las pasiones e intereses que en el momento elegido agitan a todos y a cada uno de los personajes que retrata, es una creación suya, una obra exclusiva de su fantasía que ha creado de nuevo y poetizado la realidad pasada." (Sarmiento, 1948, p. 126)

No se puede negar que la pasión emergente de los acontecimientos y discusiones provocados por el desenlace de La tablada, incentiva a José María Paz, protagonista de las guerras civiles de medio siglo, a narrar sus memorias. De hecho, la lectura de las memorias de La Madrid resultó uno de los motivos que lo empujaron a escribir su versión de los hechos. Del diálogo y de la heterogeneidad, se vale Eduarda Mansilla para introducirse en la discusión pública y aportar su lectura acerca de la construcción de la modernidad nacional. Mansilla retoma el procedimiento binario de Sarmiento y lo corrige; elabora una trama compleja no homologable al modelo acotado de civilización o barbarie. En cuanto a la pericia poética en la formulación literaria de la realidad, en nuestro caso, tomamos contacto con tres autores, la historia de la literatura -si la misma se tratara de un patrón válido- parece haber dado un veredicto: el problema de la verdad -cuestión que motivó a José María Paz y a Eduarda Mansilla a escribir- no resulta una implicatura imprescindible.

\section{Referencias}

Alberdi, J. B. (1962). Facundo y su biógrafo. En Grandes y pequeños hombres del Plata (pp. 281-394). Buenos Aires: Fernández Blanco.

Alberdi, J. B. (2006).El crimen de la guerra. Buenos Aires: Buena Vista Editores.

Andrews, J. (1827). Journey from Buenos Aires. London: Jhon Murray. Albermarle Street.

Barrico, A. (2008). El alma de Hegel y las vacas de Wisconsin. Una reflexión sobre música culta y modernidad Trad. Roana Bradaschia. Madrid: Ediciones Siruela. 
Barthes, R. (2013). La muerte del autor. En El susurro del lenguaje. Más allá de la palabra y de la escritura (pp. 75-84 ). Barcelona: Paidós.

Cohen, M. (2014). Música prosaica. En Música prosaica (cuatro piezas sobre traducción) (pp. 11-27). Buenos Aires: Editorial Entropía.

Contreras, S. (2013). ¿Cómo leer a Sarmiento escritor hoy? En A. Laera y G. Batticuore (comps.), Sarmiento en intersección: cultura, literatura y política en la Argentina (pp. 33-45). Buenos Aires: Libros del Rojas.

Foucault, M. (2001). ¿Qué es un autor? En Entre filosofia y literatura (pp. 329-360). Barcelona: Paidós.

Gilpin, W. (1792). Three essays: on picturesque beauty; on picturesque travel; and on sketching landscape: to which is added a poem, on landscape painting. London: R. Blamire. Recuperado de http://name.umdl.umich.edu/004863369.0001.000

Jitrik, N. (1977). El Facundo, la gran riqueza de la pobreza. En D. F. Sarmiento, Facundo (pp. 9-52). Caracas: Biblioteca Ayacucho.

La Madrid, G. A. (2007). Memorias del general Gregorio Aráoz de La Madrid. Buenos Aires: Ediciones Elefante Blanco.

Mansilla, E. (2007). Pablo o la vida en las pampas. Buenos Aires: Biblioteca Nacional-Ediciones Colihue - Biblioteca Nacional.

Masiello, F. (1997). La teoría de una mujer acerca del estado: Eduarda Mansilla de García. En Entre civilización y barbarie. Mujeres, nació y cultura literaria en la Argentina moderna (pp. 55-61). Buenos Aires: Beatriz Viterbo Editora.

Páez de La Torre. G. (2007). Prólogo. En G. A. La Madrid. Memorias del general Gregorio Aráoz de La Madrid (pp. 7-24). Buenos Aires: Ediciones Elefante Blanco.

Paz, J. M. (2000). Memorias Póstumas I. Buenos Aires: Emecé Editores.

Palti, E. (2004). Los poderes del horror: Facundo como epifórica. Revista iberoamericana, 52(207), 521-544. Doi: https://doi.org/10.5195/reviberoamer.2004.5565

Piglia, R. (1998). Sarmiento, escritor. En Filología. Nº 1-2 Buenos Aires. UBA. (pp.19-34).

Prieto, A. (2003). Domingo F, Sarmiento. En Los viajeros ingleses y la emergencia de la literatura argentina 1820-1850 (2. ${ }^{\mathrm{a}}$ ed.), (pp. 178-213). Buenos Aires: Fondo de Cultura Económica.

Salomón, N. (1984). Realidad, ideología y literatura en el Facundo de D. F. Sarmiento. Amsterdam: Rodopi. 
Sarmiento, D. F. (1938). Facundo. (Alberto Palcos ed.). La Plata, Argentina: Universidad Nacional de La Plata.

Sarmiento, D. F. (1948). Artículos críticos y literarios (1842-1853). En Obras Completas. Tomo 2. Buenos Aires: Luz del Día.

Sarmiento, D. F. (1977). Facundo. (Nora Dottori y Susana Zanetti eds.). Caracas: Biblioteca Ayacucho. Recuperado de https://www.clacso.org.ar/biblioteca_ayacucho/detalle.php?id_libro=1603

Sarmiento, D. F. (1996). Viajes. París: Fondo de Cultura Económica (Colección Archivos).

Shiner, L. (2015). La invención del arte. Una historia cultural. Buenos Aires: Paidós.

Tatarkiewicz, W. (2001). Historia de seis ideas. Arte, belleza, forma, creatividad, mímesis, experiencia, estética. (6. ${ }^{\mathrm{a}}$ ed.). Trad. Francisco Rodríguez. Madrid: Editorial Tecnos.

Von Humboldt, A. (1875). Cosmos. Tomo II. Bélgica: Eduardo Perié Editor. Recuperado de http://www2. fct.unesp.br/docentes/geo/bernardo/BIBLIOGRAFIA\%20DISCIPLINAS\%20POS-GRADUACAO/ALEXANDER\%20VON\%20HUMBOLT/Humboldt,\%20A.\%20Cosmos.pdf

Von Humboldt, A. (1999). Prólogo de la tercera edición. En Cuadros de la Naturaleza. México: Siglo XXI Editores. 